\title{
IMIGRAÇÃO PORTUGUESA PARA O RIO DE JANEIRO NA PRIMEIRA METADE DO SÉCULO XIX
}

Rosana Barbosa Nunes, Ph.D.*

Resumo: Os Historiadores têm ignorado a imigração portuguesa para o Brasil durante a primeira metade do século XIX. Este artigo mostra que, dentro da capital do império, a imigração portuguesa neste periodo foi um aspecto significante e foi composta por imigrantes legais, ilegais e trabalhadores endividados.

Unitermos: Portugueses, imigrantes, trabalhadores endividados e imigrantes ilegais.

\section{Introdução}

A imigração portuguesa para o Brasil tem sido uma presença constante na história brasileira. O Brasil foi o principal destino para imigrantes portugueses durante o período colonial. ${ }^{1}$ Após a independência, o Brasil continuou a atrair o maior número de emigrantes portugueses. ${ }^{2} \mathrm{Em}$ termos absolutos e segundo as estastísticas brasileiras, pelo menos 1.055 .154 portugueses entraram no Brasil desde 1820 até 1920.

\footnotetext{
" Ibero-American Studies Program. University of Toronto.

1 Jorge Carvalho Arroteia. A Emigração portuguesa - suas origens e distribuição (Lisboa: Instituto de Cultura e Língua Portuguesa, 1983), p. 23. ${ }^{2}$ Herbert Klein. "The Social and Economic Integration of Portuguese Immigrants in Brazil in the Late and Early Twentieth Century," Journal of Latin American Studies, 23, 2 (1991), p. 311.

3 Miriam Halpern Pereira. A Política Portuguesa de Emigração, 1850-1930 (Lisboa: A Regra do Jogo, 1981), p. 19.
} 
Apesar destes números, a imigração Portuguesa para o Brasil ainda não tem recebido a atenção que merece. Em particular, a primeira metade do século XIX tem sido negligenciada. Em 1992, Maria Beatriz Nizza da Silva afirmou que, para o período entre 1822 até meados do século XIX, nenhum estudo sobre a imigração portuguesa para o Brasil havia sido publicado. ${ }^{4}$ Somente as teses portuguesas de Jorge Fernandes Alves e Henrique Fernandes Rodrigues, cobrem o período da primeira metade do século XIX. ${ }^{5}$

Varios estudos tem sido publicados no Brasil sobre a imigração de outros grupos, como os italianos, os alemães e os japoneses. No entanto, o estudo sobre os portugueses como um grupo

imigrante, tem sido altamente ignorado. Este artigo irá mostrar que a imigração portuguesa para o Brasil era um movimento real. O artigo, no entanto, irá se limitar ao Rio de Janeiro. Neste sentido, o artigo tem como objetivo, provar que a capital do Império, recebeu um número significante de portugueses durante a primeira metade século XIX. Finalmente, o artigo irá também mostrar que esta cidade recebeu a maioria dos imigrantes portugueses no Brasil e por isso se tornou a mais portuguesa de todas as cidades brasileiras do Império.

\section{Historiografia}

No entanto, estudos feitos sobre a cidade do Rio de Janeiro também têm ignorado a presença portuguesa no início do século XIX. Livros clássicos, como O Rio de Janeiro do Meu Tempo de Luís Edmundo e Aparência do Rio de Janeiro de

\footnotetext{
${ }^{4}$ Maria Beatriz Nizza da Silva. Documentos para a História da Emigração Portuguesa no Brasil, 1850-1838 (Rio de Janeiro: Federação das Associações Portuguesas e Luso-Brasileiras, 1992), p. XVI.

${ }^{5}$ Henrique Fernandes Rodrigues. A Emigração do Alto Minho, 1835-1860. Tese de Mestrado, Universidade do Porto (Porto, 1991); Jorge Fernandes Alves. Os Brasileiros: Emigração e Retorno no Porto Oitocentista. Dissertação de Doutoramento. Universidade do Porto (Porto, 1993).
} 
Gastão cruls, não só enfatizam a presença francesa na cidade, a qual era extremamente inferior a Portuguesa, mas também mostram um certo desprezo em relação a população portuguesa. Luís Edmundo, numa referência indireta a presença portuguesa do Rio, descreve a população carioca como:

... descalça e mal-vestida, as suas toscas lojas de comércio (...) o homem de feição árabe, roliço e porco, ao fundo vendendo a mercadoria". ${ }^{6}$

Gastão Cruls considera os imigrantes portugueses como inferiores aos outros Europeus e os considera uma influência negativa no mercado carioca, já que estes eram donos de pequenos e pobres estabelecimentos de comércio, ao contrário dos franceses e ingleses que posuíam estabelecimentos maiores e mais elegantes. ${ }^{7}$

Estudos recentes sobre a cidade não mostram este mesmo sentimento de desprezo sobre os portugueses, mas ignoram a presença portuguesa no início do século. Por exemplo, Sidney Chalhoub, apesar de ter contribuído para o melhor conhecimento da população imigrante da cidade no século XIX, falha em entender que a imigração portuguesa não era um fenômeno do final do século XIX. Em Trabalho,Lar e Botequim, ele deveria ter olhado para a imigração portuguesa da primeira metade do século XIX para conseguir explicar como esta população chegou a totalizar $20 \%$ da população carioca em $1890 .{ }^{8} \mathrm{Em}$ Visões da Liberdade Chalhoub faz generalizações sobre a imigração portuguesa para o Rio, quando ele se refere ao grande número destes imigrantes como uma característica do final do século XIX. ${ }^{9}$ Ele deveria ter mostrado que a população

6 Luís Edmundo. O Rio de Janeiro do Meu Tempo, Vol.1, p.45.

${ }^{7}$ Gastão Cruls. Aparência do Rio de Janeiro.(Rio de Janeiro: José Olympio Editora, 1965). p.300.

${ }^{8}$ Sidney Chalhoub. Trabalho, Lar e Botequim. (São Paulo: Editora Brasiliense, 1988). p.25.

${ }^{9}$ Sidney Chalhoub. Visões da Liberdade. (São Paulo: Editora Schwarcz, 1990). pp. $199-200$. 
portuguesa do Rio de Janeiro cresceu lentamente durante todo o século XIX, incluíndo a primeira metade do século.

Gladys Sabina Ribeiro contribuíu imensamente para o melhor conhecimento da população portuguesa carioca durante a República Velha com o seu livro, Mata Galegos: os portugueses e os conflitos de trabalho na República Velha, ${ }^{10}$ no entanto, ela não menciona a imigração durante a primeira metade do século XIX. Em outro trabalho seu, o artigo "'Ser Português' ou 'Ser Brasileiro'? ${ }^{11}$ ela tenta definir o significado de ser português ou brasileiro no período da independência. No entanto, ela não discute o movimento de entrada de imigrantes portugueses na cidade e nem os possíveis números desta imigração.

\section{Fontes}

A falta de estudos sobre imigração na primeira metade do século XIX, é consequência do fato que os documentos e estatísticas que estão mais disponíveis aos historiadores cubram o período após 1850. Contribuindo para esta situação está o fato das estatísticas brasileiras sobre a entrada de imigrantes não existirem para a primeira metade do século $\mathrm{XIX}$. Por exemplo, as melhores fontes com as quais se pode estimar o número de portugueses entrados no porto do Rio de Janeiro durante este período, são os registros de passaportes existentes no Arquivo Nacional do Rio de Janeiro. No entanto, para se chegar a uma estimativa aproximada do número de imigrantes entrados no Rio de Janeiro durante as primeiras décadas do Brasil independente, foi necessário contar passaporte por passaporte de todos aqueles que se registraram ao chegar nesta cidade. Sendo assim, a realidade não é que a imigração portuguesa para o Brasil foi insignificante no período anterior a

10 Gladys Sabina Ribeiro. Mata Galegos. Os Portugueses e os Conflitos de Trabalho na República Velha. Coleção Tudo é História. (Rio de Janeiro: Brasiliense, 1990).

${ }^{11}$ Gladys Sabina Ribeiro. "'Ser Portugues' ou 'Ser Brasileiro'? Algumas Considerações Sobre o Primeiro Reinado." Ler História 25 (1994): 27-55. 
1850, mas que historiadores escolheram ignorar este período menos documentado.

Infelizmente, o Arquivo Nacional do Rio de Janeiro não possui livros de passaportes para o período desde 1843 até o final da década de 1860 . Por isso a informação para a década de 1840 será menos detalhada e para alguns anos não haverá dados disponíveis. Quadros de passageiros encontrados no Arquivo Nacional da Torre do Tombo em Portugal fornecem alguma informação sobre os anos de 1847 a 1850.

A existência dos registros de passaportes é o resultado de uma exigência brasileira do século XIX, de que todos os estrangeiros desembarcados em qualquer cidade brasileira, tinham que se registrar no departamento da polícia local. No entanto, a grande proporção de portugueses entrados no Rio de Janeiro, não se registrou. Por exemplo, de 25 de abril a 20 de junho de 1831, dos 198 estrangeiros entrados na cidade do Rio de Janeiro, somente 69 se registraram. ${ }^{12}$ No entanto, apesar dos registros de passaportes não apresentarem um quadro completo do número de portugueses entrados no Rio de Janeiro, eles demonstram que a imigração para o Rio de Janeiro era uma realidade no Brasil daquela época.

\section{Imigrantes no Rio de Janeiro: Números}

$E^{\prime}$ muito difícil determinar o número exato de imigrantes portugueses entrados no Rio de Janeiro durante as primeiras décadas após a independência brasileira, já que os imigrantes que não se registraram são invisíveis para as estastísticas. Levando-se em consideração os registros de passaportes e os quadros de passageiros de navios entrados na cidade, um total de 26.785 pode ser calculado para o período entre 1826 e 1850. Em 1841, o representante do governo português no Rio de Janeiro, Idelfonso Leopoldo Bayard, descreveu a influência portuguesa na cidade:

${ }^{12}$ Diario do Rio de Janeiro. 25 de junho de 1831. 
Nas lojas quase que não há senão caixeiros Portugueses, e também são os de escritório e os volantes nas Fazendas e nos Engenhos os Feitores e Administradores, nas casas os criados de servir, no trabalho do mar os mestres das sumacas, os arrais das faluas e Barcos e até os pescadores brancos são pela maior parte portugueses, sem falar em alguns oficiais de ofícios, Negociantes.

Ele concluiu que a demanda para trabalhadores portugueses era tão grande que qualquer imigrante poderia achar emprego em menos de oito dias após a sua chegada. ${ }^{13}$

Fontes quantitativas mostram que entre outubro de 1826 e agosto de 1827, 905 portugueses se registraram com o departamento de polícia do Rio de Janeiro. ${ }^{14}$ Para o período entre agosto de 1828 e Março de 1830, 1.200 imigrantes foram registrados. ${ }^{15}$

Estes dois livros de passaportes listavam somente imigrantes portugueses, sem incluir nenhum outro estrangeiro. Isto não significa, entretanto, que não havia outros estrangeiros morando no Rio de Janeiro na década de 1820. Em 1821, esta cidade tinha mais de 3.000 residentes estrangeiros, a maioria da França, Inglaterra, Suiça, e dos estados germânicos. ${ }^{16}$

Os registros de passaportes encontrados para o período de 1831 a 1843, listavam não somente os portugueses mas também outros estrangeiros. Estes livros indicam claramente que havia um fluxo de imigrantes portugueses no Rio de Janeiro, enquanto que imigrantes franceses, espanhóis, e ingleses eram

${ }^{13}$ Arquivo Nacional da Torre do Tombo. Ministério dos Negócios Estrangeiros. 26 de maio de 1841. Livro 720.

14 Arquivo Nacional do Rio de Janeiro. Apresentação de Passaportes de Portugueses na Polícia. Códice 378.

15 Arquivo Nacional do Rio de Janeiro. Apresentação de Passaportes de Portugueses na Polícia. Códice 379.

16 Neill Macaulay. Dom Pedro. The Struggle for Liberty in Brazil and Portugal, 1798-1834 (Durham: Duke University Press, 1986), p. 88. 
os grupos mais importantes após os Portugueses. Os registros de passaportes mostram que os Portugueses constituíam, de longe, o maior grupo de imigrantes no Rio de Janeiro durante o período estudado. Entre abril de 1831 à maio de 1842, foram listados 18.427 imigrantes Portugueses no Rio de Janeiro. Os franceses, somavam um total de somente 1.346 pessoas. Os Espanhóis e ingleses seguem com totais inexpressivos de 869 e 406 respectivamente. ${ }^{17}$ Apesar da falta de registros de passaportes para as décadas de 1840 e 1850, outras fontes indicam que 12.830 portugueses foram registrados quando entravam no Rio de Janeiro entre 1847 e 1850. (ver tabela 1)

\section{TABELA 1}

Número de Portugueses Entrando no Rio De Janeiro 1847-1850

\begin{tabular}{|c|c|c|c|c|}
\hline 1847 & $\mathbf{1 8 4 8}$ & primeiro semestre 1849 & 1850 & Total \\
\hline 3.396 & 3.189 & 1.949 & 4.296 & 12.830 \\
\hline
\end{tabular}

Fonte: Arquivo Nacional da Torre do Tombo.

Ministério dos Negócios Estrangeiros. Caixa 314.

Mapas de Passageiros vindos dos portos de Portugal e seus domínios.

Obs: Os dados para o segundo semestre de 1849 não foram encontrados.

Apesar da década de 1840 não ser muito bem representada, é possível concluir que, baseado nos dados disponíveis, houve um acréscimo no fluxo de imigrantes portugueses para o Rio de Janeiro durante o final da década de 1830 e na década de 1840 , como a Tabela 2 mostra. Jorge Fernandes Alves apoia esta idéia quando indica que na década de 1840 um maior número de portugueses escolheu o Rio de Janeiro como seu destino quando fizeram o requerimento para passaporte na cidade do Porto. ${ }^{18}$ Alguns documentos do período mostram uma estimativa do número total de imigrantes

\footnotetext{
${ }^{17}$ Arquivo Nacional do Rio de Janeiro. Apresentação de Passaportes de Estrangeiros na Poliícia. Códice 381, Volumes 1 - 16.

${ }^{18}$ Jorge Fernandes Alves. Os Brasileiros: Emigração e Retorno, Quadro 5.17.
} 
portugueses morando no Rio de Janeiro durante as décadas de 1830 e 1840 . O censo da Polícia de 1834 afirma que haviam 5.750 homens estrangeiros morando no Rio de Janeiro, incluindo 3.701 portugueses, 549 fanceses, 500 ingleses, e 1.000 de nacionalidades variadas. ${ }^{19} \mathrm{Em} \mathrm{1842}$, Idelfonso Leopoldo Bayard listou uma estimativa muito mais alta quando ele declarou que haviam por volta de 30.000 portugueses vivendo na Província do Rio de Janeiro, ${ }^{20}$ o que incluía as paróquias urbanas e rurais da cidade. Em 1846, outro representante da rainha portuguesa, José de Vasconcelos e Sousa, afirmou que havia de 20.000 a 30.000 portugueses no Rio de Janeiro. ${ }^{21}$

Uma estimativa mais precisa do número total de Portugueses morando no Rio de Janeiro na década de 1840 pode ser encontrada no censo de 1849 da municipalidade do Rio de Janeiro. Este mostra que havia 28.942 homens e 7.384 mulheres estrangeiros livres na cidade. ${ }^{22}$ Apesar destes dados se referirem a população estrangeira em geral, os portugueses constituíam a maioria desta população como as tabelas acima mostraram.

Um outro pequeno, mas interessante, indicador do tamanho da população portuguesa no Rio de Janeiro é uma lista de testemunhas chamadas a depor num inquérito sobre um incêndio numa farmácia, no centro do Rio, em julho de 1831. De vinte duas testemunhas, onze eram portuguesas, duas eram francesas, duas eram inglesas, uma espanhola, uma russa, e somente cinco eram brasileiras. ${ }^{23}$

\footnotetext{
19 Mary Karasch. Slave Life in Rio de Janeiro, 1808-1850 (Princeton: Princeton University Press, 1986), p. 63.

${ }^{20}$ Arquivo Nacional da Torre do Tombo. Ministério dos Negócios Estrangeiros. Livro 721. 16 de maio de 1842.

${ }^{21}$ Arquivo Nacional da Torre do Tombo. Ministério dos Negócios Estrangeiros. Livro 722. 1 de setembro de 1846.2

22 Arquivo Nacional do Rio de Janeiro. Mapa da População do Rio de Janeiro. Ministério do Império. Microfilme 007-1-82.

${ }^{23} \mathrm{O}$ Americano.(Rio de Janeiro). 28 de julho de 1831.
} 


\section{TABELA 2}

Média Mensal do Número de Portugueses entrando no

Rio de Janeiro

\begin{tabular}{|l|r|}
\hline De outubro 1826 a agosto 1827 & 91 \\
\hline De agosto 1828 a março 1830 & 67 \\
\hline De abril a dezembro 1831 & 77 \\
\hline De maio 1832 a abril 1833 & 78 \\
\hline De novembro 1833 a març 1834 & 195 \\
\hline De março a outubro 1834 & 70 \\
\hline De outubro 1834 a novembro 1835 & 118 \\
\hline De novembro 1835 a maio 1836 & 199 \\
\hline De maio 1836 a marçco 1837 & 175 \\
\hline De março 1837 a janeiro 1838 & 154 \\
\hline De janeiro 1838 a fevereiro 1839 & 116 \\
\hline De fevereiro a agosto 1839 & 293 \\
\hline De agosto 1839 a maio 1840 & 183 \\
\hline De maio 1840 a janeiro 1841 & 163 \\
\hline De fevereiro a dezembro 1841 & 188 \\
\hline De dezembro 1841 a fevereiro 1842 & 200 \\
\hline De abril a maio 1842 & 445 \\
\hline 1847 & 283 \\
\hline 1848 & 266 \\
\hline 1849 (primeiro semestre) & 325 \\
\hline 1850 & 358 \\
\hline
\end{tabular}

Fontes: Arquivo Nacional do Rio de Janeiro. Apresentação de Passaportes de Portugueses na

Polícia. Códice 378. Apresentação de Passaportes de Estrangeiros na Polícia. Códice 381, volumes

1 a 16. Arquivo Nacional da Torre do Tombo. Mapa de Passageiros. $1847,1848,1849$ ( $1^{\circ}$ semestre), e 1850. Caixa 314.

Fontes não quantitativas também fornecem evidências que ilustram o fluxo de imigrantes portugueses na cidade. Por exemplo, em 1826 o consul português no Rio de Janeiro, Carlos Mathias Pereira, escreveu para o ministro dos negócios estrangeiros de Portugal, o conde de Porto Santo, dizendo que todos os navios vindos de Portugal, particularmente do Porto, chegavam no Rio de Janeiro cheio de pessoas fugindo de Portugal. ${ }^{24}$

${ }^{24}$ Arquivo Nacional da Torre do Tombo. Ministério dos Negócios Estrangeiros. Livro 714. 20 de junho de 1826.

Hist. Ensino, Londrina, v. 6, p. 163-177, out. 2000 
Em 1836, o então ministro dos negócios estrangeiros em portugal, Joaquim Antonio de Magalhães, escreveu que ele tinha informações de representantes das Legações portuguesas no Rio de Janeiro, Bahia, e Pernambuco sobre o grande número de portugueses imigrando para aquelas províncias. ${ }^{25} \mathrm{Em} \mathrm{1842,} \mathrm{o}$ representante português no Rio de Janeiro, Idelfonso Leopoldo Bayard, comentou numa carta para o seu governo sobre o grande número de portugueses chegando ao porto do Rio de Janeiro. ${ }^{26}$

As fontes não-quantitativas também mostram que havia um fluxo de imigrantes ilegais para a cidade do Rio. Carlos Mathias Pereira, também afirmou que o navio português, o "Danúbio", chegou no Rio de Janeiro em 1826 não só com um grande número de imigrantes listados como tripulação mas também com 38 passageiros clandestinos, os quais tencionavam permanecer no Rio ilegalmente. ${ }^{27}$

A prática de capitães de navios em trazerem imigrantes ilegais para o Brasil disfarçados de tripulantes, era comum durante a primeira metade do século $\mathrm{XIX}^{28}$ Jorge Fernandes Alves tem afirmado que existia um fluxo de emigrantes ilegais de Portugal para o Brasil durante todo o século XIX e que haviam várias embarcações envolvidas no transporte de passageiros clandestinos do Porto para o Brasil. ${ }^{29}$ Em novembro de 1859, o representante português no Rio de Janeiro, Conde de Thomar, acusou o capitão e proprietário do navio "Nova Lima" de trazer imigrantes clandestinos da llha de São Miguel, que não possuíam passaportes para o Rio de Janeiro. ${ }^{30}$

\footnotetext{
${ }^{25}$ Arquivo Nacional da Torre do Tombo. Ministério dos Negócios Estrangeiros. Livro 593. 19 de maio de 1836.

${ }^{26}$ Arquivo Nacional da Torre do Tombo. Ministério dos Negócios Estrangeiros. Livro 716. 22 de agosto de 1842.

27 Arquivo Nacional da Torre do Tombo. Ministério dos Negócios Estrangeiros. Livro 714. 20 de junho de 1826.

${ }^{28}$ Arquivo Nacional da Torre do Tombo. Ministério dos Negócios Estrangeiros. Livro 595. 30 de julho de 1842.

29 Jorge Fernandes Alves. Os Brasileiros: Emigração e Retorno, p.203.

${ }^{30}$ Citado por Miriam Halpern Pereira. A Política Portuguesa de Emigração, p. 81.
} 
Os documentos disponíveis não são claros no que se constituía um "imigrante ilegal". O termo parece que significava pessoas que saíram de Portugal sem passaporte, como também, indivíduos que não se registraram na sua chegada ao Brasil. Isto não necessariamente indicava uma intenção criminosa. Jorge Fernandes Alves explica que em Portugal algumas pessoas simplesmente decidiam evitar o longo e dispendioso processo para a aquisição de um passaporte. Outros emigravam sem passaporte como maneira de fugir ao recrutamento militar no exército português. ${ }^{31}$

Muitas das pessoas que emigravam sem passaporte eram pessoas sem recursos que viajavam para o Brasil com algum tipo de subsídio. Muitos eram subsidiados pelos capitães de navios nos quais eles viajavam, os quais faziam um negócio lucrativo com o transporte de imigrantes. Depois da sua chegada ao Brasil esses imigrantes eram aliciados como trabalhadores endividados por qualquer pessoa que estivesse disposta a pagar as despesas de viagem do recém-chegado. Neste caso, os imigrantes ficavam devendo dinheiro aos seus patrões até serem capazes de saldar a dívida previamente feita. ${ }^{32}$

Apesar de não haver informações detalhadas sobre os indivíduos que vinham ao Brasil desta maneira nem sobre as condições por eles econtradas no Brasil, documentos do período sugerem que havia um número significante de navios envolvidos neste "tráfico". Por exemplo, no dia 14 de outubro de 1835, o representante português na Bahia, Domingos de Castro Ferreira e Sousa, escreveu para o Duque de Palmela, que um navio dos Açores com destino ao Rio de Janeiro, havia chegado a Bahia no início do mês por causa da falta de mantimentos no navio, trazendo muitos imigrantes aliciados em Portugal. Ferreira Sousa declarou que

\footnotetext{
31 Jorge Fernandes Alves. Os Brasileiros: Emigração e Retorno, p.213.

32 Revista Universal Lisbonnense. (Lisboa) Tomo III, 1843/1844. p. 231. Arquivo Nacional da Torre do Tombo. Ministério dos Negócios Estrangeiros. Caixa 197. 14 de outubro de 1835 .
} 
Alguns destes mesmos infelizes trazem passaportes para Lisboa, outros os não trazem para parte alguma, e muito poucos o trazem para o Rio de Janeiro.

Ele continuou dizendo que os passageiros, miseráveis e iludidos em sua presença celebrassem contratos que não importam nada menos que a alienação de suas liberdades às pessoas que quissessem pagar-lhes as exorbitantes passagens.

A situação, Ferreira Sousa continuou, provocou comentários entre o povo local que eram ofensivos aos portugueses. Um negociante disse:

Eu julgo que não convém dar ao capitão da Escuna $50 \$$ ou $60 \$ 000$ réis para deixar sair um desses escravos de libambo, senão com a condição de servir pelo menos 20 anos a seu senhor, pois não sendo assim antes comprar um preto por $300 \$ 000$ ou $400 \$ 000$ réis que pode servir por toda a vida.

Outro comentário pejorativo veio de um francês que disse:

Eu sinto bem ter comprado ainda há pouco um preto africano, porque se não o tivesse feito teria agora ocasião de comprar um português. ${ }^{33}$

Um mês depois, o representante da Legacão portuguesa no Rio de Janeiro escreveu para o Duque de Palmela dizendo que "em todos os navios provenientes do Porto e dos Açores se exportam para aqui duzentas e mais pessoas tanto dum como d'outro sexo com as quais se trafica a sua chegada como se fossem Africanos." ${ }^{34}$ Incidentes como estes levou ao governo

${ }^{33}$ Arquivo Nacional da Torre do Tombo. Ministério dos Negócios Estrangeiros. Caixa 197. 14 de outubro de 1835.

${ }^{34}$ Arquivo Nacional da Torre do Tombo. Ministério dos Negócios Estrangeiros. Livro 718. 10 de novembro de 1835. 
português em 1843 a tentar parar este tipo de trabalho forçado. Este proibiu a detenção de qualquer passageiro pelo capitão do navio na sua chegada a qualquer porto estrangeiro. ${ }^{35}$

No entanto, imigrantes portugueses continuaram a serem trazidos e "vendidos" por capitães de navios como trabalhadores forçados. Através da década de 1840 a Revista Universal Lisbonnense publicou vários artigos condenando a emigração de pessoas que não tinham meios de pagar as despesas de viagem. Em 1844, a mesma revista condenou os capitães de navios que levavam emigrantes enganados do Porto e ilhas portuguesas, "tratando-os atrozmente na viagem (...) os probrezitos que ficam a bordo por não terem podido pagar, levanta-lhes o capitão o preço (...) se não vende todos (...) vai a outro porto procurar veniaga." ${ }^{36}$ Em setembro de 1849 outro artigo criticou a emigração de portugueses levados por capitães de navios dizendo que "há casos em que essa emigração é uma verdadeira escravidão."37 Aparentemente este sistema continuou na década de 1850. LuizFelipe de Alencastro escreveu que após a abolição do tráfico brasileiro de escravos, alguns traficantes continuaram com o seu "negócio" trazendo trabalhadores portugueses, principalmente dos Açores, para o Brasil. ${ }^{38}$

\section{Destino}

Apesar de não se ter informações prescisas sobre os indivíduos que imigraram sem passaportes, a realidade é que a grande maioria dos imigrantes portugueses, que possuíam passaportes, se dirigiram para o Rio de Janeiro. Estudos que examinam as areas de grande emigração portuguesa - as províncias do Douro e Minho - mostram que a maioria dos

\footnotetext{
${ }^{35}$ O Echo do Rio (Rio de Janeiro). 11 de novembro de 1843.

${ }^{36}$ Revista Universal Lisbonnense, Tomo III, 1843/44. p. 231.

37 Revista Universal Lisbonnense, 2a Série, Tomo I, 1848/49. p. 518.

38 Citado por Sidney Chalhoub. Visões da Liberdade: Uma História das Últimas Décadas da Escravidão na Corte (São Paulo: Editora Schwarcz, 1990), p. 200.
} 
emigrantes destas regiões escolheram como destino o Rio de Janeiro. Esta informação é relevante já que a maioria dos imigrantes portugueses listados nos registros de passaportes entre os anos de 1831 e 1842, eram de origem nortenha, especialmente do Minho e Douro. ${ }^{39} \mathrm{Na}$ sua tese sobre emigração no Porto, Jorge Fernandes Alves mostrou que, de 1836 a 1850 , Rio absorveu entre $60 \%$ e $86 \%$ de todos imigrantes portugueses no Brazil. ${ }^{40}$ Henrique Fernandes Rodrigues no seu estudo sobre passaportes no Minho concluíu que mais de $56 \%$ dos imigrantes estudados por ele, declararam a intenção de se dirigir para o Rio de Janeiro, enquanto que $36.5 \%$ deixaram Portugal com o destino geral de "Brasil", sem especificar a cidade ou a província para onde esses se dirigiam. ${ }^{41}$ É muito provavel que entre esses, uma maioria significante também tenha imigrado para o Rio de Janeiro.

\section{Conclusão}

Uma análise precisa dos registros de passaportes do Arquivo Nacional do Rio de Janeiro, mostra que a imigração para o Rio de Janeiro era um aspecto bastante real durante a primeira metade do século XIX. Entre os imigrantes entrados na cidade neste período, os portugueses constituíam a grande maioria. Franceses. espanhóis e ingleses eram os outros grupos mais numerosos de estrangeiros na cidade. No entanto, estes constituíam uma pequena minoria na população imigrante da cidade, já que cerca de $80 \%$ de todos os imigrantes registrados na cidade eram portugueses.

${ }^{39}$ Arquivo Nacional do Rio de Janeiro. Apresentação de Passaportes de Portugueses na Polícia. Códice 378. Apresentação de Passaportes de Estrangeiros na Polícia. Códice 381.

40 Jorge Fernandes Alves. Os Brasileiros: Emigração e Retorno no Porto Oitocentista. Dissertação de Doutoramento. Universidade do Porto. (Porto, 1993). Quadro 5.17.

${ }^{41}$ Henrique Fernandes Rodrigues. A Emigração do Alto Minho, 1835-1860, p. 234. 
A imigração portuguesa para o Rio de Janeiro foi constante durante todo o século XIX. No início da República Velha, uma grande proporção da população carioca era de origem portuguesa. $\mathrm{Na}$ verdade, os portugueses foram o único grupo imigrante que manteve um movimento migratório espontâneo e contínuo para o Rio de Janeiro não somente durante o século XIX mas também durante boa parte do século $X X$.

Abstract: Historians have ignored Portuguese immigration to Brazil, during the first half of the 19th Century. This article shows that, within the capital of the Empire, Portuguese immigration in this period was significant and was made up of legal and illegal immigrants and indentured workers.

Keywords: Portuguese, immigrants, indentured workers, and illegal immigrants. 